\title{
CINEMA E FUTEBOL: DOS GRAMADOS PARA AS TELAS
}

\author{
Daniel Machado ${ }^{1}$ \\ Luís Gustavo Finger de Oliveira ${ }^{2}$ \\ Fabiana Quatrin Piccinin ${ }^{3}$
}

\begin{abstract}
RESUMO
Este artigo apresenta o estudo de investigação que incorre na questão da construção do personagem protagonista. Neste aspecto destaca-se que tanto o futebol quanto o cinema, ao longo de suas trajetórias, percorreram caminhos semelhantes até alcançarem o status de entretenimento por grande parte da população no século XXI. O futebol e o cinema chegaram ao Brasil como atividades da elite. Porém, com o passar dos anos as duas formas de entretenimento atraíram a atenção da população brasileira. Neste contexto, pode-se olhar para dois grandes mitos do futebol nacional que se destacaram nas décadas de 40, 50 e 60 e que se sucederam no Botafogo: Heleno e Garrincha. Em razão disso, a partir da produção cinematográfica nacional sobre a história desses jogadores, busca-se analisar a partir da teoria da narrativa o filme Heleno, dirigido por José Henrique Fonseca no ano de 2011, e Garrincha, do diretor Milton de Alencar e lançado em 2003. Para observação dos filmes foram selecionados elementos comuns presentes em ambos os filmes e relacionados ao desempenho das personagens protagonistas, como por exemplo, a relação destes com o futebol, com a fama, com os relacionamentos, com o declínio/doenças.
\end{abstract}

Palavras-chave: Narrativa. Personagem. Construção. Cinema.

\begin{abstract}
This article proposes the narrative investigation of football in cinema and the question of construction of the main character. Both the football and the cinema, by the time of their trajectories traveled very similar paths to achieve the status of entertainment for much of the population in the XXI century. Near the end of the nineteenth centuries, the football and cinema came to Brazil from Europe, as activities of the elite people. However, over the years, the two modes of entertainment attracted a attention of the brazilians. In this situation, we can looks at two great myths of national football who have excelled in the 40, 50 and 60, being two idols that succeeded in Botafogo: Heleno and Garrincha. As a result, through the national film about the life history of these players we try to execute the analysis from narrative theory in the study of Heleno movie directed by José Henrique Fonseca in 2011 and Garrincha directed by Milton Alencar and released in 2003. For observation of the movies were selected common elements present in both films and related to the performance of the main characters, such as the relationship of the same with football, with fame, with relationships, the decline and diseases.
\end{abstract}

Keywords: Narrative. Character. Construction. Cinema.

\footnotetext{
${ }^{1}$ Acadêmico de Comunicação Social - Habilitação Produção em Mídia Audiovisual da Universidade de Santa Cruz do Sul - UNISC. <danielms@mx2.unisc.br>

2 Acadêmico de Comunicação Social - Habilitação Jornalismo da Universidade de Santa Cruz do Sul - UNISC. <lgfinger@mx2.unisc.br>

${ }^{3}$ Professora do Mestrado em Letras e do Departamento Comunicação Social da Universidade de Santa Cruz do Sul UNISC.<fabi@unisc.br>
} 


\section{A PERSONAGEM NA NARRATIVA}

Para conhecer algo a respeito da personagem, é essencial que seja dada atenção à construção textual, a forma como o autor optou para compor suas criaturas, e a partir daí observar sua independência, autonomia e a "vida" destes seres de ficção. Através destes elementos, do descobrimento das experiências vividas pelas personagens, que poderemos desvendar a existência da personagem como representação de uma realidade externa ao texto.

No debate sobre personagem-pessoa, os autores em geral procuram salientar dois pontos essenciais, quais sejam: (a) o problema da personagem é, antes de tudo, um problema linguístico, pois ela não existe fora das palavras; e (b) as personagens representam pessoas, segundo modalidades próprias da ficção (BRAIT, 2002, p.11).

Este ser habita uma realidade ficcional, portanto o conteúdo de que é construído e o espaço onde habita é diferente do conteúdo e espaço dos seres humanos, ainda que ambas as realidades mantenham um relacionamento intrínseco. Isto fez com que a personagem se consolidasse em um caminho entre a dicotomia ser reproduzido/ser inventado (BRAIT, 2002).

Seja a concepção de personagem, seja a sua função no discurso, ambas estão diretamente ligadas não apenas à mobilidade criativa do fazer artístico, mas especialmente à reflexão a respeito dos modos de existência e do destino desse fazer. A reflexão sobre a questão da personagem significa, necessariamente, analisar estudos e pesquisas já realizadas pela crítica com o intuito de estabelecer seu objeto e buscar a metodologia adequada à análise e à fundamentação dos juízos acerca desse objeto.

Um fator importante dos estudos da personagem é o que diz respeito à analogia existente entre personagem e pessoa, conceito que foi discutido na mimesis aristotélica. Por muito tempo, a palavra mimesis foi interpretada como "imitação do real", fazendo alusão específica e direta à criação de uma semelhança ou imagem da natureza, concepção que perdurou por anos como definição de caracterização e valoração da personagem.

Nessa linha de pensamento, Massaud (1970) define os seres de ficção como pessoas que vivem dramas e situações dentro da narrativa, como se fossem seres vivos, idênticos a nós. No entanto, como são representações verbais, ilusões ou sugestões, recebem o nome de "personagens".

É relevante prestar atenção em dois aspectos essenciais: 
- a personagem como reflexo da pessoa humana;

- a personagem como construção, cuja existência obedece às leis particulares que regem o texto.

Na obra de Brait (2002), este cita o escritor inglês Philip Sidney, que considera que as artes possuem valor na medida em que guiam a uma ação virtuosa e que a personagem, neste sentido, deve ser a reprodução do melhor do ser humano. Porém, o conceito elaborado por Sidney em transmitir a personagem como um ser idêntico, mas ainda melhor de seu modelo humano, encontra adeptos em outros teóricos.

A partir da segunda metade do século XVIII, nota-se a ascensão de uma visão que busca compreender a personagem como representação do universo psicológico de seu criador. Essa mudança de perspectiva ocorre devido a uma série de condições que se sucederam no final do século XVIII e durante todo o século XIX. É nesse instante que o sistema de valores da estética clássica começa a declinar, perdendo a sua homogeneidade e a sua rigidez. É também nesse momento que o romance evolui e se transforma ao mesmo tempo em que ocorre a afirmação de um novo público - burguês —, caracterizado, entre outras coisas, por um gosto artístico singular.

Na era moderna, Lukács (1920) apresenta uma nova visão de personagem, contudo, apesar de reacender o debate a respeito do tema e de se diferenciar da teoria aristotélica e horaciana, ele sujeita a estrutura do romance e consequentemente da personagem, à influência determinante das estruturas sociais. Porém, mesmo trazendo uma nova perspectiva acerca de personagem, a concepção permanece na linha do modelo humano.

Forster (1969) busca esclarecer alguns pontos relacionados ao romance e ao personagem de ficção. O romancista e crítico inglês, apesar de todas as suas outras obras, tornou seu livro fundamental no que diz respeito à personagem devido à sua divisão das personagens em flat plana, tipificada, sem profundidade psicológica - e round, redonda, complexa, multidimensional. Ou seja, conforme Forster (1969), as personagens, reconhecidas no conjunto da obra, podem ser definidas em planas e redondas. As personagens planas são construídas ao redor de uma única ideia ou qualidade, geralmente são definidas em poucas palavras, não estão sujeitas à evolução no decorrer da história, de forma que as suas ações apenas confirmem a impressão de personagens estáticas, não reservando qualquer surpresa ao leitor.

De acordo com Brait (2002, p. 41), as personagens classificadas como redondas possuem como característica mais saliente a complexidade "apresentando várias qualidades ou tendências, 
surpreendendo convincentemente o leitor. São dinâmicas e multifacetadas, constituindo imagens totais e, ao mesmo tempo, muito particulares do ser humano".

Ao contrário das planas, as redondas possuem profundidade que se revela por uma série de características identificadas pelo desenvolvimento variável de uma virtude ou um vício. As coisas se passam dentro delas e não a elas, por isso causam surpresa ao leitor, devido a essa "flexibilidade" psicológica, semelhante à dos seres humanos.

Brait busca explicar a maneira como o escritor realiza a construção da personagem e a forma de utilização de recursos com intuito de conceber suas criaturas.

\footnotetext{
Quer elas sejam tiradas de sua vivência real ou imaginária, dos sonhos, dos pesadelos ou das mesquinharias do cotidiano, a materialidade desses seres só pode ser atingida através de um jogo de linguagem que torne tangível a sua presença e sensíveis os seus movimentos (BRAIT, 2002, p. 52).
}

O narrador em terceira ou em primeira pessoa proporcionará diferentes formas de transmissão da construção das personagens. Pode, assim, apresentar-se como um indivíduo não envolvido na história, fazendo o papel de uma câmera de vídeo, ou pode apresentar-se como uma personagem envolvida direta ou indiretamente com os fatos narrados. Com isso fica o questionamento de qual for a forma como o narrador se colocará na história, em ambas ele se tornará um ponto de vista capaz de caracterizar as personagens.

Entende-se que para construir progressivamente a imagem do personagem na mente do leitor/espectador é preciso combinar de forma harmônica a formação do espaço, a estruturação do ambiente, a caracterização da postura física da personagem e a utilização do discurso indireto livre para expor os pensamentos e as emoções desse ser fictício. Brait (2002) afirma que um escritor habilidoso consegue descobrir maneiras de unir recursos à narrativa em terceira pessoa de modo a tornar suas criaturas verossímeis e aceitáveis na mente do público.

Para o efeito de realidade ganhar corpo é necessária uma descrição detalhada de traços que indicam a estrutura física das personagens, a escolha do nome desses seres, a descrição dos movimentos, as roupas e a linguagem de cada um.

Conforme reitera Brait (2002, p. 58),

a descrição, a narração e o diálogo funcionam como os movimentos de uma câmera capaz de acumular signos e combiná-los de maneira a focalizar os traços que, 
construindo essas instâncias narrativas, concretizando essa existência com palavras, remetem a um extratexto, a um mundo referencial e, portanto, reconhecido pelo leitor.

Para Renata Pallottini (1989) a personagem é construída pelo poeta a partir da realidade, entretanto, a personagem não reúne todos os detalhes possíveis de serem encontrados em um ou muitos seres humanos, seus espelhos. A autora traz para a definição a linha de pensamento aristotélica que determina a personagem como imitação e, portanto, a reprodução das características mais marcantes de uma ou mais pessoas, traços, que segundo Pallottini (1989), são selecionados pelo poeta conforme seus próprios critérios.

$\mathrm{Na}$ área da dramaturgia, um fator bastante discutido é o referente à verossimilhança e a coerência da personagem. Aristóteles, em sua obra Poética (1997), diz que os seres de ficção devem ser bons, convenientes, semelhantes (ou verossimilhantes), coerentes e, talvez, mais claramente, necessários.

Porém, a mencionar a bondade das personagens, a intenção do pensador não é afirmar que elas devem ser obrigatoriamente cheias de virtudes, bondosas, doces, delicadas, ternas - pelo menos não em tempo integral. Quando fala em seres ficcionais bons, o pensador grego tem a intenção de dizer que eles devem ser bem concebidos, planejados de forma consistente e adequados para os fins da ação. Com isso, entende-se que as personagens devem ter uma boa estrutura, um bom esqueleto, devem ter um objetivo final de pensamento (dianóia, pensamento ou discurso), pelo qual expressarão aquilo que realmente planejam realizar, conforme os princípios do seu caráter (ethos) (PALLOTTINI, 1989).

Uma história fantástica construída segundo os princípios do autor vai aos poucos formando cenários, regras e conceitos no imaginário do público que, após algum tempo da imersão na narrativa acaba aceitando, por exemplo, que as personagens voem, soltem lasers pelos olhos ou então que não se machuquem. Ou seja, a verossimilhança é construída conforme a organização do texto elaborada pelo dramaturgo.

Em uma narrativa, o grupo de personagens deve ser de total domínio do autor, bem como seus comportamentos e seus sentimentos. Mesmo que todo esse conhecimento acerca das personagens não apareça na própria obra, o autor deve saber tudo a respeito de suas criaturas, desde aparência física até suas preferências, de seus vícios às suas virtudes. Como diz Pallottini (1989, p. 62), “o conjunto de personagens é uma verdadeira constelação, onde as estrelas de maior brilho supõem a existência de pequenos e quase apagados astros menores". 
A caracterização de uma personagem deve ser harmônica ou se tornar coerente diante de nossos olhos. Ao contrário, caso se torne estranha no decorrer da história, o autor deverá mostrar que essa desarmonia possui um propósito a ser alcançado, uma lógica que seja aceitável pelo público. O personagem deve se se apresentar como um ser viável, plausível e passível de aceitação pelo imaginário do público.

A exposição da criatura em sociedade conduz a outra caracterização, a psicológica. Nesse quesito insere-se o modo de ser da personagem, sua constituição psicológica, sua afetividade, emoções, sentimentos, bem como a capacidade de tomar decisões e manter a palavra, persistência, força de vontade, defeitos e virtudes marcantes. Enfim, todos os fatores que concernem à psiqué da personagem.

Pode-se perceber que, assim como no ser humano, a construção de um ser fictício também sofre interligações - o psicológico leva ao social, o físico leva ao psicológico e assim por diante. É importante saber que a construção de uma personagem é um processo de estruturação de um ser humano fictício, mais ou menos cheio de detalhes, conforme o tipo de texto, mas sempre coerente e capaz de convencer da existência desse ser criado. Assim, seja ela apresentada pelo ângulo físico, psicológico, social ou outros, a caracterização é uma união de detalhes sistematizados que buscam solidificar uma estrutura de ser humano.

\section{PROTAGONISTA E ANTAGONISTA}

Partindo de uma análise etimológica da palavra protagonismo (proto = principal, primeiro; agon = luta; agonistes = lutador), julga-se protagonista um ser que age especificamente no processo de evolução pessoal e de transformação da sua própria realidade, assumindo um papel central, ou seja, de ator principal. Ele é a personagem principal de uma narrativa, seja ela literária, cinematográfica, teatral ou musical. Em torno dela é que se desenvolve a trama e a ação das outras personagens, ou seja, as principais ações são realizadas por ela ou sobre ela.

Já antagonista é a personagem que cria o clima de tensão, ela contraria-se ao protagonista. Ao construir uma narrativa, nunca se deve desprezar o antagonista, pois o sucesso de uma narrativa está essencialmente associado à qualidade de caracterização desse personagem. 
Protagonista e antagonista são definidos, principalmente, na linguagem popular como mocinho e bandido. Em outros termos, herói e vilão. Dada a natureza da maioria das obras de ficção, o protagonista é, realmente, na maioria das vezes, um herói ou ao menos uma pessoa com mais qualidades do que defeitos. Ou, como nos casos de vilão ou anti-herói, o protagonista pode seguir, na narrativa, uma moral própria, diferente das impostas na sociedade em que vive. Em nossa literatura é muito frequente o anti-herói como protagonista. Macunaíma é um exemplo do herói sem nenhum caráter, ou seja, o anti-herói. Em consequência das ações dos protagonistas, em muitas obras perde-se a noção de bem ou mal. É importante salientar que nem sempre o mocinho da história vai ser o protagonista da narrativa, podendo ser considerado, inclusive, o vilão da trama, conforme o ponto de vista do leitor/telespectador.

No teatro grego, quem introduziu o protagonista foi o dramaturgo grego Ésquilo, que foi o primeiro a colocar dois atores representando papéis opostos e dialogando entre si. O protagonista pode ser também um indivíduo, uma dupla ou até mesmo um grupo - é aquele que protagoniza seu próprio drama. Representa a si mesmo e seus personagens são parte dele. Palavra e ação se integram, expandindo as formas de abordagem.

Considerados personagens fundamentais na maioria dos acontecimentos de uma narrativa, protagonista e antagonista são contrárias na linguagem teatral, literária, novelística, cinematográfica e qual for o gênero onde se possam construir personagens. O primeiro é o que possui papel de destaque na trama, ou seja, é o elemento principal do enredo em questão. $\mathrm{O}$ segundo também se destaca na obra, mas nem sempre é um ser humano, pode ser um obstáculo na vida do protagonista em forma de pessoa, animal, problema, entre outros.

Os personagens encarnados em antagonista e protagonista situam-se juntos ao longo da narrativa, pois, geralmente, um atrapalha o outro a atingir seus objetivos. Isto é, um agindo como o mocinho e o outro exercendo o papel de vilão, respectivamente, caracterizando o protagonista e o antagonista. Entretanto, em algumas situações acontece a troca de papéis preestabelecidos, ou seja, a personagem principal é o canalha da história, enquanto o antagonista é o representante do bem.

Ao olharmos para o passado, mais especificamente para a tragédia grega, descobrimos que a definição do bem ser representado pelo protagonista e o mal pelo antagonista se deu em grande medida no teatro grego. Os dicionários em geral, nas definições aos respectivos vocábulos, definem o antagonista como "pessoa que é contra alguém ou algo; adversário, 
opositor" e o protagonista como "personagem principal" e até mesmo "pessoa que desempenha ou ocupa o primeiro lugar num acontecimento". Além da divisão entre os representantes de cada papel, o vilão, em forma de ser humano que cria obstáculos ou muitas vezes ele mesmo sendo o próprio obstáculo, serve de incentivador para o mocinho alcançar seus objetivos.

\section{HELENO E GARRINCHA SEGUNDO A TEORIA}

Para Melo (2006), o futebol, assim como cinema, também é uma forma de arte. Neste sentido, a comparação entre os jogadores de futebol e os atores de cinema se dá na medida em que os dois são tratados como astros e constantemente são procurados para estrelarem propagandas que lhe permitam grande visibilidade. Também pode ser destacado como semelhante a existência dos treinamentos e ensaios, para que os jogadores e atores possam se preparar e posteriormente exibirem suas capacidades no mais alto nível. Porém, apesar das semelhanças, no futebol não há a possibilidade de repetir a jogada que deu errado, ao contrário do cinema. Ainda assim, pode-se dizer que ambas atuam num palco, numa performance endereçada aos espectadores.

Fernandes (2011) afirma também que outra dimensão de ambos os setores diz respeito ao fato de que cinema e futebol movimentam um grande comércio de produtos e estilos que são divulgados tanto pelas estrelas dos filmes, quanto dos gramados e pela mídia. Além disso, a Copa do Mundo e a entrega do Oscar ocupam o status de alguns dos maiores eventos mundiais da atualidade, atribuindo ao futebol e ao cinema o caráter de espetáculo.

Neste contexto de semelhanças, se pode olhar para dois grandes ídolos do futebol dos anos 40, 50 e 60, retratados recentemente pelo cinema nacional. Trata-se de Heleno (2011) e Garrincha (2003), personalidades míticas do futebol brasileiro. Em um tempo que o futebol tinha uma conotação mais romântica, jogadores mais amadores e o amor à camisa eram muito mais presentes. Assim, a partir das personagens de Heleno e Garrincha, retratados pelo cinema, buscase compreender o lugar dos protagonistas nestes filmes que apresentam a história destes jogadores, marcada pela fama e pela vida conturbada.

Para investigar como se constrói uma personagem (protagonista), a primeira visada se dá pela literatura e posteriormente empreende-se a análise para o cinema. Tanto na literatura quanto 
no cinema, a personagem é uma representação da pessoa, do ser humano e a construção desta vem se modificando e evoluindo ao longo do tempo.

Há vários tipos de personagens espalhados na literatura: protagonista, antagonista, confidente, dinâmico, uma longa lista os quais auxiliam seus autores a conduzirem suas narrações. E esta categorização também pode servir para o entendimento do conceito de personagem no teatro e nos filmes. Em todas estas obras temos a narração dos acontecimentos e a situação das personagens no enredo. Mas, diferente dos livros, podemos ver e ouvir o personagem, não apenas fazer o uso da imaginação para ter uma pequena caricatura deste em nossa mente.

Como citado anteriormente, a personagem plana é criada com um único conceito e qualidade, suas ações e comportamento são repetitivos, não desenvolve sua personalidade ao longo da obra. Por essa razão a personagem plana já é previsível desde o início até o final de seus atos.

Diferente da personagem plana, a personagem redonda possui uma personalidade forte, é complexa. São mais próximas do ser humano, pois são ricas em qualidades e defeitos, suas ações e caráter podem se alterar ao longo da narrativa, decaindo ou evoluindo de acordo com o seu psicológico. Segundo o filme, Heleno e Garrincha se enquadram nas características da personagem redonda, pois ambos apresentam comportamentos complexos, como medos, atitudes explosivas, dilemas, dúvidas, alegrias, enfim, uma "montanha russa" de sentimentos.

Um dos fatores que comprovam Heleno como personagem redondo, e condiz com o que a teoria afirma, é que o jogador, mesmo formado em Direito, rico, vaidoso, famoso, mulherengo, adepto da boemia e frequentador dos salões glamorosos da alta classe do Rio de Janeiro da década de 40 e 50, era adepto dos exageros, viciado em cigarro e éter, que mais tarde o destruiriam.

Garrincha seguia um comportamento parecido, menos explosivo e superior ao de Heleno. O jogador fazia o tipo moleque. Logo em seu primeiro treino pelo Botafogo, humilhava, com seus dribles, Nílton Santos, jogador de Seleção e de maior destaque do time na época.

Assim como Heleno, achava que não precisava treinar. E anos mais tarde do início de sua carreira, por se considerar um dos melhores, também começou a não aceitar salários menores do que outros jogadores da equipe, apresentando, nesse momento, semelhanças com a arrogância de Heleno, seu antecessor no posto de ídolo do clube carioca. 
Após a conquista da Copa do Mundo no Chile em 1962, os jornais já estampavam o relacionamento do jogador com a célebre cantora Elza Soares. Garrincha, após conhecer Elza durante o torneio e assumir o relacionamento, parou de comparecer aos treinamentos do clube carioca, bebia excessivamente e rebatia as críticas dizendo que seu treino era com sua mulher. Que, quando entrava nos gramados após ter estado com ela entrava leve, com fome de bola e preparado para fazer um espetáculo.

Para Maciel (2003), um dos maiores segredos para se criar um bom personagem no cinema é a identificação do roteirista com a personagem. O roteirista tem de ser capaz de ver o mundo com olhos da personagem. Logo quando ele escreve seus atos e seus diálogos, deve ser ele próprio desenvolvendo tais ações.

Neste sentido Pallottini (1989) destaca que o nome da personagem é fundamental, muitas vezes sendo, como no caso de Heleno e Garrincha, tão importante característica quanto qualquer outra coisa. Isso se verifica no próprio nome dos filmes, que recebem os nomes dos próprios jogadores, "Heleno - O príncipe maldito" e "Garrincha - Estrela Solitária".

A personalização de uma personagem deve ser feita de forma harmônica. Caso contrário, deve apresentar uma lógica própria para esta desarmonia da personagem, uma proposta coerente. De nada adianta o autor compor o personagem com vários detalhes, se para o ponto de vista do telespectador, ele não se mostrar um personagem viável e passível de aceitação pela imaginação. Quanto mais verossímil, melhor (PALLOTTINI, 1989).

Conforme o longa-metragem (2011), o futebol é considerado a maior paixão da vida de Heleno - o futebol para ele era algo vital A adrenalina causada pela imprevisibilidade do jogo o atraía e sua personalidade impetuosa aliada ao seu comportamento arrogante causava diversas desavenças no plantel. Nunca se responsabilizava pela derrota, mas sempre pela vitória. A vontade de vencer fazia o jogador ter comportamentos explosivos com seus companheiros de time, os culpava de forma ofensiva e bruta, ao mesmo tempo que tentava explicar o sentido e a importância de estarem jogando e vestindo a camisa do Botafogo, cobrando-os a mesma vontade de vencer que ele tinha. Com gênio forte, gerava desavenças na equipe. Sua permanência se tornou insustentável, sendo vendido para o Boca Juniors da Argentina. Suas atitudes e a briga com técnico Flávio Costa o impediram também de realizar um de seus maiores sonhos: jogar a Copa do Mundo de 1950. 
Acreditava que só deveriam receber o dinheiro em caso de vitória e, se ela não viesse, Heleno atormentava-se em seus pensamentos buscando esquecer a derrota que tanto o machucava. Como pode ser observado, os filmes retratam as atitudes dos dois jogadores perante diversas situações que aparecem em suas vidas, concordando dessa forma com a teoria, que afirma, mesmo após ser roteirizado, o personagem, no cinema, só vai se completar quando o mesmo tiver uma função efetiva, na relação entre o personagem e sua experiência concreta.

Assim, é preciso que se estabeleça a função dramática do personagem que Maciel (2003) classifica em agentes (protagonista e antagonista), ajudantes (confidentes - ajudam a desenvolver os agentes), comentadores (desdobramento de outros personagens) e emblemas (personagens secundários - figurantes).

Kothe (1987), assim como Pallotini, também defende a verossimilhança e por isso destaca que

as obras de arte precisam ser verdadeiras e a verdade pode ser horrível, como também pode ser encantadora. O horrível pode ser o resplendor da verdade. Não podendo ser malfeitas, as obras de arte não podem ser belas simplesmente no sentido de enfeitadas, embelezadas. A verdade, concretizando fantasmas, mesmo que por um percurso de sangue, suor e lágrimas, acaba trazendo a calma e a tranquilidade da sabedoria (KOTHE, 1987, p. 29).

Seguindo a linha de pensamento elaborada pelo autor, fica evidente o drama pessoal de Heleno retratado no filme, sendo o futebol posto em segundo plano. Pouco popular com as gerações mais novas, o longa procura resgatar a imagem do que é considerado o primeiro jogador-problema do futebol brasileiro, apresentando-o como ser humano complexo e interessante, com dilemas, problemas, vitórias, medos e alegrias. O drama de Heleno é retratado já no início do longa-metragem, no manicômio em Barbacena. A cena mostra o jogador observando recortes de jornal que mostram seus feitos e vitórias, buscando na memória, lembranças de um passado glorioso e intenso.

De acordo com a personagem retratada no filme, Heleno teve uma carreira meteórica. $\mathrm{O}$ jogador teve rápida ascensão e, do mesmo modo, a queda a partir da decadência física e mental. Sem conseguir andar direito e ser dono de suas faculdades, passou a sobreviver de lembranças dos áureos tempos em que tinha saúde, alegria e domínio de seu corpo, até morrer em novembro de 1959.

Outro fator importante para construção deste sentido de verdade do personagem protagonista é a sua caracterização. A maneira como se comporta em relação aos outros 
indivíduos, como age em grupo, em sociedade e em seus relacionamentos amorosos ou profissionais. Isto leva à caracterização psicológica, o modo de ser do personagem, sua afetividade, emoções, sentimentos. Capacidade de fazer opções e mantê-las, persistência, teimosia. Força de vontade, defeitos, virtudes marcantes. Enfim, tudo aquilo que se está ligado à alma (psique) (PALLOTTINI, 1989).

O filme retrata um Heleno que desafiava tudo e a todos, dirigentes, médicos e amigos, para ele, suas atitudes eram as corretas e teimava em não tratar da doença para poder continuar fazendo o que mais gostava: jogar futebol. Heleno e futebol tinham uma relação intrínseca e intensa. Assim como toda a sua vida, no final da trama o jogador utiliza uma frase que escancara sua personalidade: Heleno, bêbado, doente, é melhor do que qualquer 11 pernas de pau.

Já Garrincha foi apadrinhado por Nílton Santos, que mais tarde se tornaria seu grande amigo. Mané, como também era conhecido o craque das pernas tortas, era manchete dos jornais, o ídolo de uma nação, a alegria do povo. O jogador se declarava como viciado em sexo e deixava Nair, a primeira mãe de seus filhos em Pau Grande, junto de cinco meninas, para viver em um apartamento no Rio com Iraci, que aceitava ser sua amante, e não só isso, se conformava em ver seu homem com dançarinas e cantoras de hotel como Angelita Martinez. As histórias relatadas no filme permitem um recorte das atitudes de Garrincha com os outros indivíduos, corroborando ainda mais a sua definição de personagem redonda. Era capaz de fazer amigos e ser bem quisto por eles, ao mesmo tempo em que abandonava sua esposa, apresentando duas atitudes nãolineares que se confrontam.

Para Campbell (1988), nas milhares de histórias contadas no mundo ao longo dos séculos e por culturas totalmente diferentes, há sempre uma sequência semelhante entre elas. Alguém que encontrou ou fez algo que o restante da humanidade não estava apto a fazer e não conseguiria, sendo esse alguém o herói. É alguém que deu sua vida por algo maior que ele mesmo. Campbell (1988) influenciou muitos artistas no cinema com sua obra mais conhecida, O herói de mil faces, na qual esclarece a ideia do herói que parte de seu mundo, se aventura e passa por problemas longe de casa, enfrenta inimigos e depois de algum tempo retorna tendo feito algo magnífico.

Nos filmes de Heleno e Garrincha pode-se perceber que o conceito de Campbell (1988) é seguido até certo capítulo em um roteiro. O que o autor não mencionava seria o seu final. Duas belas histórias, de dois grandes atletas, de dois grandes personagens, que não terminaram da maneira como todos gostariam de ver. 
Assim como afirma Kothe (1987),

\begin{abstract}
O que ajuda a engrandecer o herói épico é a sua dimensão trágica. O herói épico é o sonho de o homem fazer a sua própria história; o herói trágico é a verdade do destino humano; o herói trivial é a legitimação do poder vigente; o pícaro é a filosofia da sobrevivência feita gente (KOTHE, 1987, p. 15).
\end{abstract}

Declara também que quando se quer criar um personagem apenas com qualidades e comportamentos admiráveis, acaba-se construindo um ser artisticamente baixo e sem veracidade perante os olhos do público, pois se desvia do comportamento natural dos seres-humanos. (KOTHE, 1987)

A teoria construída por Kothe (1987) pode ser comprovada também no filme de Garrincha, pois apresenta as dificuldades vividas por ele. $\mathrm{O}$ alcoolismo, a pesada crítica por parte da imprensa contra o casal, bem como o golpe militar que agravou a situação de Garrincha e Elza, colaboraram para eles se mudarem para a Itália, como forma de fugirem de todos os problemas. Elza pedia que o jogador prometesse largar a bebida, mas de nada adiantava. O jogo de despedida de Mané aconteceu no Maracanã ao som de cento e trinta mil pessoas que entoavam seu nome, porém, isso também não serviu para tirar o antigo craque das garrafas de cachaça.

Acostumado a vencer, Garrincha deitava-se em uma cama de uma clínica de reabilitação e sob as lágrimas de seu companheiro de clube Nílton Santos. O jogador não conseguia mais reconhecer o antigo amigo que o futebol tinha lhe proporcionado. A alegria do povo, o demônio das pernas tortas perdia o jogo mais importante -, em 1983, perdia o jogo da vida.

\title{
4 CONCLUSÃO
}

A partir das relações entre cinema e futebol buscou-se neste artigo estudar a construção da personagem em narrativas cinematográficas brasileiras específicas e analisar como a personagem principal é retratada.

Por meio de um resgate histórico da chegada do cinema e do futebol no Brasil, nota-se que, mesmo originários da elite, logo caíram nas graças do público brasileiro e se popularizaram. No ano de 1908 esses dois meios de cultura se entrelaçam e deram origem ao primeiro filme brasileiro sobre futebol: uma derrota brasileira para a seleção argentina por 3 x 2 . Depois disso seriam necessários mais de vinte anos para que o futebol e o cinema voltassem a se encontrar. 
Utilizando de uma base teórica sobre a teoria narrativa e do cinema, pode-se observar a dificuldade de construir uma narrativa cinebiográfica, podendo o longa-metragem exagerar em determinados aspectos e acabar apresentando uma imagem forçada da vida do jogador. Infelizmente, nos dias atuais, é o que cada vez mais está fadado a acontecer: a ficção contribui para a venda do material, o público tende a se interessar por aquilo que choca, que dá assunto. Prefere o personagem real, de atitudes humanas e que age por impulso, levando em conta a emoção ao invés da razão. Segundo entrevista de Chico Anysio no livro Futebol Brasil Memória de Nogueira (2006), o futebol não dá humor, nem cinema, porque não se faz jogo de mentira.

Heleno e Garrincha, considerados os dois primeiros jogadores-problemas do futebol brasileiro, seguem uma sequência narrativa típica da teoria do Herói, construída por Campbell (1988) em "o Herói de mil faces". Porém, se diferenciam no clímax da história, na qual, ao invés de alcançarem a redenção e a glória, alcançam a vergonha e derrota. Após suas grandes conquistas pessoais e profissionais, ambos os jogadores não conquistam a vitória, mostrando, dessa forma, a vida como ela é, não só de finais felizes.

Outro fator inferido é que não se pode fazer cinema sozinho, independente de talento e de profissionalismo, o cinema é uma arte coletiva, assim como não se joga futebol individualmente, é um jogo de equipe. É possível, inclusive, estabelecer uma outra relação entre cinema e futebol. Uma bola sem jogadores não se tem jogo e o cinema sem narrativa e personagens também se torna inviável, isto é, são elementos que para darem certo precisam estar em união. Tanto o futebol, quanto o cinema já foram mais românticos nas décadas passadas, o futebol praticado por amor e o cinema sendo produzido como arte, mas não se pode negar que mesmo nos dias atuais, quando são misturados, se engrandecem e encantam o público, especialmente quando construídos a partir de personagens tão complexos como no caso de Heleno e Garrincha.

\section{REFERÊNCIAS}

BRAIT, B. A personagem. 7 ed. São Paulo: Ática, 2002.

CAMPBELL, J. O herói de mil faces. São Paulo: Círculo do Livro, 1988.

FERNANDES, V. L. P. Futebol e Cinema: que semelhanças são essas?. Ano 16, $\mathrm{n}^{\circ} 155$ Revista Digital, 2011. Disponível em: <http://www.efdeportes.com/efd155/futebol-e-cinema-quesemelhancas-sao-essas.htm> Acessado em: 17 de Agosto de 2013 
FORSTER, E. M. Aspectos do romance. Porto Alegre: Globo, 1969.

KOTHE, F. R. O herói. 2 ed. São Paulo: Ática, 1987.

LOURO, G. Cinema como Pedagogia. In: LOPES, M.; FARIA FILHO, L.; VEIGA, C. (Orgs.) 500 Anos de Educação no Brasil. 3 ed. Belo Horizonte: Autêntica, 2003.

MACIEL, L. C. O poder do clímax: fundamentos do roteiro de cinema e TV. Rio de Janeiro: Record, 2003.

MELO, V. A. Futebol e Cinema: Duas paixões, um planeta. 2006. Disponível em: <http://www.lazer.eefd.ufrj.br/producoes/futebol_cinema_artigo_livro_2006.pdf > Acesso em: 14 de ago. de 2013

MASSAUD, M. A criação literária: introdução à problemática da literatura. 3 ed. São Paulo: Melhoramentos, 1970.

MURAD, M. Futebol e Cinema no Brasil: um enredo. Revista de História, São Paulo, n. 163, p. 191-206, 2010. Disponível em: <http://revhistoria.usp.br/images/stories/revistas/163/RH_163__09_-_Maurcio_Murad.pdf> Acesso em: 13 de ago. de 2013

PALLOTTINI, R. Dramaturgia: a construção do personagem. São Paulo: Ática, 1989. 